OB Martin Wolff

\title{
Grußwort zum Internationalen Symposium „Die Confessio Augustana im ökumenischen Gespräch“
}

\section{Oktober 2019, 17:00 Uhr, Stiftskirche Bretten}

(anwesend: Kurt Kardinal Koch, Präsident des päpstlichen Rates zur Förderung der Einheit der Christen, Rom, Erzbischof Stephan Burger, Prälat der Ev. Landeskirche für Nordbaden Prof. Dr. Traugott Schächtele)

Eure Eminenz, hochverehrter Herr Kardinal, Eure Exzellenz, sehr geehrter Herr Erzbischof, Hochwürdiger Herr Prälat, Prof. Schächtele, Sehr geehrte Pfarrer Becker-Hinrichs und Maiba, verehrte Gäste aus Nah und Fern, meine sehr verehrten Damen und Herren,

dass die Augsburger Bekenntnisschrift, die Confessio Augustana, ein besonderes und bedeutendes Dokument ist, ist in die Seelen der Brettener Christen aller Konfessionen tief eingeschrieben. Schon seit 1986 die neuere Öffnung des Melanchthonhauses für die Öffentlichkeit begonnen hatte, ist Melanchthon, der Verfasser der Confessio Augusta, als „,bedeutendste ökumenische Gestalt der Reformationszeit“ im Bewusstsein der Zeitgenossen präsent. Nicht umsonst hatte der Brettener Gemeinderat im Jahr 1988 den ersten Melanchthonpreis dem Schüler Joseph Ratzingers, des späteren Papstes Benedikt XVI., Siegfried Wiedenhofer, einem katholischen Theologen verliehen, der gleichwohl durch seine Habilitationsschrift viel zum ökumenischen Verständnis der Theologie Melanchthons beigetragen hatte. Gerade das vergangene halbe Jahrhundert verdeutlicht, dass die Kirchen, die evangelische wie die katholische, ein negatives Image von Melanchthon grundsätzlich abgelegt haben. Ja, Melanchthon wird in der öffentlichen Wahrnehmung ebenso wie in der wissenschaftlichen als ein Universalgelehrter, als ein Mensch des Ausgleichs und des Augenmaßes, als jemand, der in der Suche nach dem Erhalt der Einheit der Kirche bis zum Äußersten zu gehen bereit war - eben als „größte ökumenische Gestalt der Reformationszeit“ gewürdigt, wie dies erstmals der skandinavische Reformationshistoriker Jorge Larsen im Jubiläumsjahr 1960 formuliert hatte.

In der Zwischenzeit haben die Melanchthonstadt Bretten und die „Europäische Melanchthon-Akademie“ selbst durch vielfältige Symposien, Kongresse, Forschungen und Ausstellungen zu diesem neuen Melanchthonbild beigetragen.

○ OpenAccess. (C) 2022 OB Martin Wolff, publiziert von De Gruyter. (cc) BY-NC-ND Dieses Werk ist lizenziert unter einer Creative Commons Namensnennung - Nicht kommerziell - Keine Bearbeitung 4.0 International Lizenz. https://doi.org/10.1515/9783110683868-004 
So zeigt etwa das neue Melanchthon-Handbuch, das eine Art Bilanz des neuen Melanchthonbildes im Reformationsjahr 2017 darstellt, dass das Netzwerk der neueren Forschungen zu Melanchthon über die ganze Welt gespannt ist. Die Entscheidung, den Auftakt des neuerlichen Bemühens um die Confessio Augustana hier in der Melanchthonstadt zu machen, scheint mir eine kluge Wahl, gerade weil hier die Bedeutung dieser Bekenntnisschrift von den Christen verstanden wird.

Deshalb ist es mir eine tiefe Freude, dass mit dem jetzigen Symposium ein neuer Impuls für künftige Dialoge verliehen werden kann. Das Symposium verfolgt ja das Ziel, die Confessio Augustana, dieses grundlegende Bekenntnisdokument der evangelischen Kirchen, in ein ökumenisches Gespräch zu bringen mit dem Ziel der Anerkennung, dass es sich bei dieser Schrift um den Ausdruck wahrer Katholizität der Wittenberger Bewegung handelt. Die Vorzeichen dafür scheinen günstig: Wir in Bretten denken dankbar an das Reformationsjahr 2017 zurück, das wir - übrigens wie die ganze Badische Landeskirche - in einem durchgängig ökumenischen Geist begangen hatten. Dass sich Christen aller Konfessionen gemeinsam dem Thema der Reformation zuwenden, ist ja ohnehin schon ein außerordentlich ökumenisches Zeichen, das zeigt, dass die vergangenen Konflikte, die Europa im 16. und 17. Jahrhundert in vielfältige Glaubenskriege gestürzt hatten, ihre Gültigkeit für heute verloren haben.

Die Referenten des Symposiums haben in den vergangenen drei Tagen eine Fülle von Fragen im Zusammenhang der CA und ihrer Bedeutung für die Kirchen heute diskutiert. Und den Verantwortlichen war von Anfang an klar, dass es sich hiermit nicht mehr als um einen Auftakt handeln kann, der zu weiteren Diskussionen in Kirchen, Gemeinden und in der Theologie führen muss. Es ist von hier aus wünschenswert, dass weitere Diskussionen folgen. Wenn es dann in dieser Folge zu einer solchen ökumenischen Anerkennung der Katholizität der Confessio Augustana im Jahr 2030 käme - das wäre ein äußerst wichtiger Schritt für die Kirchen in der Zukunft.

Ich freue mich, dass Sie alle den Weg in die Melanchthonstadt gefunden haben. Insbesondere danke ich Ihnen, sehr geehrter Herr Kardinal, dass Sie selbst nachher mit ihrem Vortrag die Position der römisch-katholischen Kirche verdeutlichen werden. Seien Sie mir alle sehr herzlich in der Melanchthonstadt willkommen. 